\title{
Brincadeira em Escola de Ensino Fundamental: Um estudo observacional
}

\author{
Sheila Tatiana Duarte Cordazzo \\ Josielly Pinheiro Westphal \\ Fernanda Balem Tagliari \\ Mauro Luís Vieira \\ Universidade Federal de Santa Catarina
}

\begin{abstract}
RESUMO
O brincar é uma atividade muito comum durante a vida cotidiana das crianças e pode indicar aspectos relevantes do desenvolvimento infantil. Nesse sentido, o ato de observar o que as crianças fazem durante as brincadeiras é um recurso importante que pode fornecer detalhes para a compreensão do mundo infantil. Este estudo teve como objetivo identificar formas de interação social e tipos de brincadeiras apresentados pelas crianças quando expostas a diferentes tipos de brinquedos no contexto escolar. Participaram do estudo onze crianças com idade entre sete e oito anos matriculadas em escola da rede privado de ensino. Durante três meses as crianças foram observadas (em uma sala onde estavam dispostos conjuntos de brinquedos) duas vezes por semana em sessões que duravam trinta minutos. Foram utilizadas as técnicas de observação do sujeito focal e a do registro de comportamento por amostragem de tempo. Cada criança foi observada durante 20 intervalos, de cinco segundos em cada sessão. Por meio da análise dos dados constatou-se que as crianças têm preferência por brincar em grupo e segregadas por sexo. Além disso, o brinquedo didático foi o menos utilizado. Hipóteses para explicar esses dados são apresentadas e também são analisadas as implicações do brincar no cotidiano escolar.
\end{abstract}

Palavras-chave: brincadeiras; escola; desenvolvimento infantil; diferenças de gênero.

\begin{abstract}
Play Behavior In Elementary School: An observational study

Play is a usual activity in the daily life of children and it can indicate relevant aspects of child development. Observing what children are doing during play is an important tool that can provide information for understanding the child's world. This study aimed to identify ways of social interaction and types of play behavior exhibited by children when exposed to different types of toys in the school context. Participants comprised of eleven children aged between seven and eight years enrolled in the school network of private schools. The children were observed for three months (in a room with various sets of toys) twice a week in sessions that lasted thirty minutes. Observation techniques related to focal subject and behavior recording by time sampling were used. Each child was observed during 20 intervals of five seconds in every session. Through data analysis, it was found that children have a preference for playing in groups, segregated by sex. Moreover, the educational toy was the least used. Hypotheses to explain these data are presented and implications of playing in the school everyday are analyzed.
\end{abstract}

Keywords: play behavior; school; child development; gender differences.

O brincar é um recurso que pode auxiliar os profissionais da educação e da saúde a desenvolverem as potencialidades e as habilidades das crianças. Dessa forma, a utilização do brincar nas escolas é de suma relevância, uma vez que o objetivo das escolas, não é apenas a transmissão de conteúdos escolares, mas também a formação e o desenvolvimento de um cida- dão de forma integral. As características do desenvolvimento infantil podem ser identificadas através da observação dos tipos de brincadeiras das crianças. $\mathrm{O}$ ato de observar as brincadeiras das crianças é um recurso, ou uma ferramenta de trabalho, que fornece detalhes sobre os aspectos do desenvolvimento das crianças, bem como as formas como elas interagem 
socialmente, suas preferências e diferenças individuais. Apesar dessas afirmações, algumas lacunas são encontradas nas pesquisas que investigam a brincadeira infantil. Biscoli (2005) e Cordazzo, Martins, Macarini e Vieira (2007) constataram que os estudos sobre o brincar geralmente são focados em crianças mais jovens, como bebês e pré-escolares. Os autores afirmam que as características do brincar das crianças em idade escolar necessitam ser mais investigadas. A investigação do brincar das crianças em idade escolar se apresenta como mais um recurso para a compreensão do desenvolvimento infantil e suas peculiaridades. Uma forma de demonstrar a importância do brincar para o desenvolvimento da criança é analisá-lo a partir da interação social que nele ocorre.

Durante a interação social a criança adquire habilidades como a comunicação e a regulação de emoções (Carvalho \& Pedrosa, 2002; Silva, Pontes, Silva, Magalhães \& Bichara, 2006). As relações sociais que a criança observa e participa servem como modelos a serem usados na construção de suas futuras interações (Bobato, 2002). Por meio das interações sociais a criança estabelece relação com outras pessoas e com o mundo físico à sua volta ao mesmo tempo em que percebe as questões sociais e o comportamento das outras crianças. Pedrosa e Carvalho (1995) afirmam que a interação social é atualmente vista como constitutiva do desenvolvimento cognitivo e da interação com o mundo físico. Nessa regulação mútua as crianças passam a experimentar novos papéis e a observar quais são mais aceitos pela sociedade. Morais, Otta e Scala (2001) afirmam que nas relações que a criança estabelece com o grupo de companheiros estão em jogo habilidades essenciais e a possibilidade de experimentação do poder da criança no grupo, das estratégias para exercer esse poder, assim como do exercício de mecanismos para obter aceitação e para manter sua posição no grupo.

As diferenças entre os gêneros que ocorrem nas interações sociais durante o brincar foram observadas por Wanderlind, Martins, Hansen, Macarini e Vieira (2006). A pesquisa teve como objetivo caracterizar o ato de brincar de crianças escolares em uma brinquedoteca identificando os diferentes brinquedos mais utilizados entre meninos e meninas. Os resultados foram semelhantes aos encontrados por Bjorklund e Pellegrini (2000) e mostraram que há a existência de segregação e estereotipia no brincar infantil, indicando que meninos tendem a brincar entre si e as meninas também. Os meninos brincavam mais com jogos sociais, brinquedos que reproduzem o mundo técnico (miniaturas, carrinhos, helicópteros) e fantasias. As meninas brincavam mais com brinquedos responsáveis pelo desenvolvimento afetivo (bonecas, bebês, roupinhas), jogos sociais e fantasias. Nos grupos mistos os autores verificaram uma predominância da utilização dos jogos sociais, das fantasias e dos brinquedos que reproduzem o mundo técnico. Observa-se, portanto que a segregação dos sexos nas brincadeiras está intimamente relacionada com os diferentes tipos de brincadeiras. Ou seja, além de brincarem de forma segregada, meninos e meninas também brincam de maneiras diferentes (Bjorklund \& Pellegrini, 2000).

De modo geral, crianças brincam de diferentes formas e os tipos de brincadeiras vão se modificando em função da idade e do número de parceiros. Por exemplo, crianças solitárias tendem a brincar mais de faz-de-conta, pois através da brincadeira imaginativa, criam companheiros a fim de satisfazer necessidades sociais (Kishimoto, 1998). O faz-de-conta permite não só a entrada no imaginário, mas a expressão de regras implícitas que se materializam nos temas da brincadeira (Kishimoto, 1998). O faz-de-conta propicia para a criança o desenvolvimento da adoção da perspectiva do outro e o treino da inversão de papeis sociais, bem como a linguagem empregada nesses papéis.

Outro tipo de brincadeira é a construtiva em que as crianças utilizam blocos para construir algo, ou empilham peças de dominó para formar um castelo, etc. Kishimoto (1998) afirma que os jogos de construção são considerados de grande importância por enriquecer a experiência sensorial, estimular a criatividade e desenvolver habilidades da criança. Por outro lado, os jogos de regras correspondem às brincadeiras em que a regra prepondera, embora apareçam também componentes sensório-motores ou de construção presentes (Morais, 2004). O jogo de regra pressupõe a existência de parceiros e um cumprimento de obrigações, o que lhe confere um caráter eminentemente social (Wajskop, 1996). Os jogos de regras envolvem regularidade, herdando dos jogos de exercício o prazer funcional da repetição. Mesmo aparentando ter um objetivo final a ser alcançado, a vitória, o jogo de regras pode ser considerado como comportamento de brincar, pois como afirma Brougére (1998) o mais importante no jogo não é o fim, mas o processo, e este processo envolve prazer.

Uma modalidade de brincadeira que gera confusão entre os pesquisadores principalmente pela dificuldade em observar as suas características é a brincadeira turbulenta. O brincar turbulento pode ser facilmente confundido com a agressão (Smith, 1997). Contudo, a brincadeira turbulenta difere de uma luta real, ou de uma agressão principalmente pelos sinais emitidos nas 
faces dos parceiros. Durante a brincadeira turbulenta o sorriso permanece na face dos parceiros. Exemplo de brincadeira turbulenta são as chamadas "lutinhas", onde duas ou mais crianças rolam no chão, mantém contato físico intenso, mas nenhuma delas se machuca. Conforme Papalia, Olds e Feldman (2006), 10\% das brincadeiras das crianças escolares envolvem atividades vigorosas, que podem ser interpretadas por brincar turbulento.

Como pode ser constatada, a brincadeira, independente da sua modalidade, é uma rica fonte de estímulo para o desenvolvimento infantil, para o surgimento das interações sociais e para a descoberta das habilidades e potencialidades das crianças. Uma vez que os estudos sobre o brincar se apresentam restritos quando se tratam de crianças em idade escolar (Cordazzo \& cols., 2007), se constata a necessidade de investigar, nesta pesquisa, características e tipos de brincadeiras mais utilizadas por estas crianças. Também serão identificadas as formas de interação social que as crianças utilizam quando expostas à diferentes tipos de brinquedos no contexto escolar. Além disso, pretendese apresentar reflexões sobre possíveis implicações para o desenvolvimento infantil das diferentes formas de interação social durante os episódios lúdicos e dos tipos de brincadeiras escolhidos pelas crianças.

\section{MÉTODO}

\section{Participantes}

Participaram do estudo 11 crianças (4 meninas e 7 meninos), com idades entre 7 e 8 anos. As crianças estudavam em uma turma do terceiro ano do ensino fundamental de uma escola da rede privada de ensino no município de Florianópolis (SC). As crianças foram selecionadas aleatoriamente em forma de sorteio.

\section{Procedimentos}

Inicialmente o projeto foi submetido à análise do Comitê de Ética em Pesquisa com Seres Humanos da UFSC. Foi aprovado com o número 313/06. Após esse procedimento e somente após o consentimento assinado pelos pais é que as crianças foram comunicadas da pesquisa.

As crianças foram convidadas a participar das sessões de brincadeiras livres com brinquedos diversificados. No total, foram escolhidos 23 brinquedos: balões, tiro ao alvo, boliche, iô-iô, corda, pião, elástico, varetas, quebra-cabeça, blocos de construção, jogo da memória, jogo didático de matemática, jogo didático de português, cubrick, ludo, jogo das argolas, damas, trilha, fantoches, bonecas, mico-preto, dominó e
Super-trunfo. A escolha desses materiais teve como base proposta elaborada pela International Council for Children's Play (ICCP) (Michelet, 1998), que inclui distintas 'famílias' (ou grupos) de brinquedos envolvendo atividades físicas, intelectuais e relações sociais.

O cenário das observações era composto por uma sala, previamente montada pelas pesquisadoras, dentro do ambiente escolar. A sala dispunha de algumas mesas e cadeiras onde eram colocados os brinquedos. Por um período de três meses as crianças eram encaminhadas, duas vezes por semana, para a sala com os brinquedos para as sessões de brincadeiras. Cada sessão tinha a duração de 30 minutos e foram realizadas 20 sessões no total.

A decisão sobre quem observar foi feita por meio da técnica de observação de sujeito focal e quando observar ocorreu através do registro de comportamento por amostragem de tempo. As crianças eram observadas, em forma de rodízio, em intervalos intercalados de cinco segundos. Mais especificamente, a pesquisadora observava uma criança durante 5 segundos e gastava mais 5 segundos para fazer o registro no protocolo de observação. Em seguida, a pesquisadora observava outra criança durante mais 5 segundos e depois de registrar os dados passava para a terceira criança e assim por diante. Ao terminar o ciclo de observar todas as onze crianças, a pesquisadora retornava para a primeira criança que tinha observado. A pesquisadora repetia esse rodízio por 20 vezes consecutivas. Sendo assim, ao final da sessão, cada criança tinha sido observada durante 20 intervalos. No total, cada criança foi observada, em média, durante 325 intervalos.

Três pesquisadoras foram previamente treinadas para a realização das observações. Para garantir a confiabilidade dos dados foi realizado o teste de concordância entre observadores. A primeira sessão em cada amostra foi designada para a realização do teste de concordância. Tal procedimento se faz necessário para garantir um grau mínimo de acordo entre os observadores no que se refere ao uso de um conjunto de categorias predefinidas (Kreppner, 2001). O teste de concordância entre observadores necessitou da realização de um estudo piloto durante uma sessão de brincadeira livre em cada amostra. Durante esta sessão três observadores registraram os comportamentos das mesmas crianças ao mesmo tempo. De acordo com Fagundes (1999) foi considerado como confiável um índice de concordância entre os observadores acima de $70 \%$. O índice médio obtido entre as três pesquisadoras foi de $86 \%$, sendo que o índice mínimo atingiu $75 \%$ de concordância. 


\section{Categorias}

Com base nos dados obtidos no estudo piloto e em uma busca teórica foram estabelecidas as categorias de observação. Elas foram divididas em três núcleos principais que se referem à: a) interação social, b) tipo de brinquedo e c) tipo de atividade. A mensuração dos dados foi realizada através da somatória da frequência e da média dos intervalos observados em cada categoria.

a) Quanto à interação: Com base nos estudos de Parten (1933), Carvalho, Alves e Gomes (2005) e Lordelo e Carvalho (2006) foram selecionados três sistemas comportamentais no que se refere à interação social: não ocorrência de interação social (que pode ser de forma solitária ou paralela); e a ocorrência de interação (definida como atividade de grupo). Definições mais específicas sobre essas categorias podem ser encontradas em artigo anterior (Cordazzo, Westphal, Tagliari, Vieira \& Olivieira, 2008). No caso da interação social, o grupo que interagia com a criança focal era registrado. Ou seja, o número e o sexo dos parceiros envolvidos na brincadeira eram quantificados.

b) Quanto aos brinquedos: As crianças estavam em situação de brincar livre, em uma sala de aula regular na qual estavam disponíveis alguns brinquedos para que elas os utilizassem, ou não, em suas brincadeiras. Ao todo eram 28 brinquedos categorizados em três tipos: cognitivo, social e motor. Esta categorização seguiu as normas da classificação de brinquedos proposta pela ICCP, descrita por Michelet (1998). Descrições detalhadas sobre essa classificação também podem ser encontradas em Cordazzo e cols. (2008). Dentre os brinquedos cognitivos foi acrescentada uma subcategoria, a dos brinquedos didáticos. Por se tratar de observações realizadas no ambiente escolar achou-se conveniente registrar a frequência de utilização destes tipos de brinquedos como uma categoria a parte.

c) Quanto ao tipo de atividade: No que se refere à atividade executada pela criança focal foram definidas primeiramente duas grandes categorias: a brincadeira e a não brincadeira. Estas duas categorias são divididas em subcategorias que apontam os comportamentos específicos da criança focal. A brincadeira é definida como qualquer atividade estruturada, desempenhada pela criança, que gera prazer, que possui um fim em si mesmo e que pode ter regras implícitas ou explícitas, conforme apontam autores como Baptista da Silva (2003), Bomtempo (1997), Brougère (1998) e Vygostky (1998). As subcategorias do brincar consideradas no presente estudo foram: brincadeira construtiva, faz-de-conta, jogos de regras e brincadeira turbulenta. Defi- nições detalhadas sobre essas categorias podem ser encontradas em artigo anterior (Cordazzo \& cols., 2008). Também foi registrado se a criança estava utilizando o brinquedo de acordo com a proposta do objeto, ou seja, a sugestão de brincadeira que o fabricante do objeto sugere, com suas regras e procedimentos. Neste caso a criança poderia estar não apenas brincando, mas também montando ou desmontando o brinquedo de acordo com as instruções sugeridas pelo fabricante do objeto.

Comportamentos de não brincadeira foram definidos como quaisquer atividades diferentes daquelas que foram incluídas na categoria de brincadeira, como por exemplo: comportamento desocupado, exploração, agressão, entre outras. Definições específicas e considerações sobre essas categorias podem ser encontradas em Cordazzo e cols. (2008). Nesse artigo também se encontra disponível o formulário de observação que foi utilizado na presente pesquisa.

\section{Análise dos dados}

Com o intuito de verificar as diferenças ocorridas entre os registros das observações dentro das categorias de cada núcleo foi utilizada a ANOVA de um fator para medidas repetidas com o teste de efeito Greenhouse-Geisser e o teste Bonferroni para comparar os pares de médias. As diferenças entre meninos e meninas foram comparadas com a utilização do teste $t$ de Student para amostras independentes.

\section{RESULTADOS}

Os primeiros dados analisados se referem às características das interações sociais apresentadas pelas crianças durante as observações. As crianças investiram mais tempo, durante as sessões de brincadeira livre, interagindo de forma grupal do que não interagindo. A análise da diferença entre as médias foi realizada através de uma ANOVA de um fator para medidas repetidas. $\mathrm{O}$ teste de efeito dentre os sujeitos Greenhouse-Geisser apontou que as diferenças entre as três médias foram altamente significativas $(\mathrm{F}(1,11)=59,28, p \leq 0,01)$. As crianças passaram cerca de $80 \%$ dos intervalos observados em interação grupal $(\mathrm{M}=272,55 \pm 90,76), 7 \%$ de forma solitária $(\mathrm{M}=$ $37,73 \pm 33,50)$ e 11 em interação paralela $(\mathrm{M}=24,55$ $\pm 8,73)$.

Para verificar as diferenças entre cada média foi utilizado o teste Bonferroni que revelou não ser significativa a diferença entre as médias na categoria referente à não interação social (solitária e paralela). 
Contudo, foi encontrada diferença altamente significativa $(p \leq 0,01)$ quanto à utilização da interação de grupo em relação às outras categorias. Ou seja, as crianças demonstraram utilizar muito mais a interação social grupal nas suas atividades.

A escolha do sexo dos parceiros por parte das crianças também foi analisada. As crianças apresentaram preferência altamente significativa por brincar com parceiros do mesmo sexo $(F(1,0)=55,53, p \leq 0,01)$. Ao analisar as diferenças entre meninos e meninas se constatou que os meninos têm uma forte tendência para a segregação, independente do número de parceiros nas atividades. $\mathrm{O}$ teste $t$ para amostras pareadas apontou que, em todos os cruzamentos entre número e sexo de parceiros nas atividades, foram encontradas preferências altamente significativas $(p \leq 0,01)$ por parte dos meninos para preferir parceiros do mesmo sexo. Entre as meninas os resultados encontrados foram diferentes. Nas observações das meninas foram encontradas diferenças significativas somente na variável que envolvia vários parceiros na atividade $(t(3)=11,90 ; p \leq 0,01)$. O que indica que as meninas preferiam brincar com vários parceiros quando estes eram do mesmo sexo.

Como as crianças estavam sendo expostas à situações de brincadeiras livres na escola, o tipo de brin- quedo utilizado nas suas atividades também foi alvo das observações. Brinquedos relacionados com o desenvolvimento motor foram os mais escolhidos, com 33\% dos intervalos observados, seguido dos brinquedos cognitivos $(24 \%)$, social $(21 \%)$. A modalidade de brinquedo didático foi a menos utilizada pelas crianças observadas (4\%). Em 18\% dos intervalos observados as crianças não estavam utilizando brinquedos.

Para avaliar a diferença entre as médias das cinco categorias referentes ao tipo de brinquedo utilizado pelas crianças durante as observações foi realizada a ANOVA de um fator para medidas repetidas. Foram encontradas, pelo teste de efeito dentre os sujeitos Greenhouse-Geisser, diferenças significativas entre as cinco categorias observadas $(F(2,21)=7,05, p \leq 0,05)$. O teste de comparação dos pares de médias (Bonferroni) indicou que as crianças utilizam menos as modalidades de brinquedos didáticos quando comparados com os outros tipos de brinquedos $(p<0,05)$. As diferenças das médias dentre as outras modalidades de brinquedos não se mostraram significativas. A distribuição da utilização dos brinquedos pelos diferentes sexos também foi analisada. A Figura 1 apresenta as diferenças de sexo no que se refere ao tipo de brinquedo utilizado.

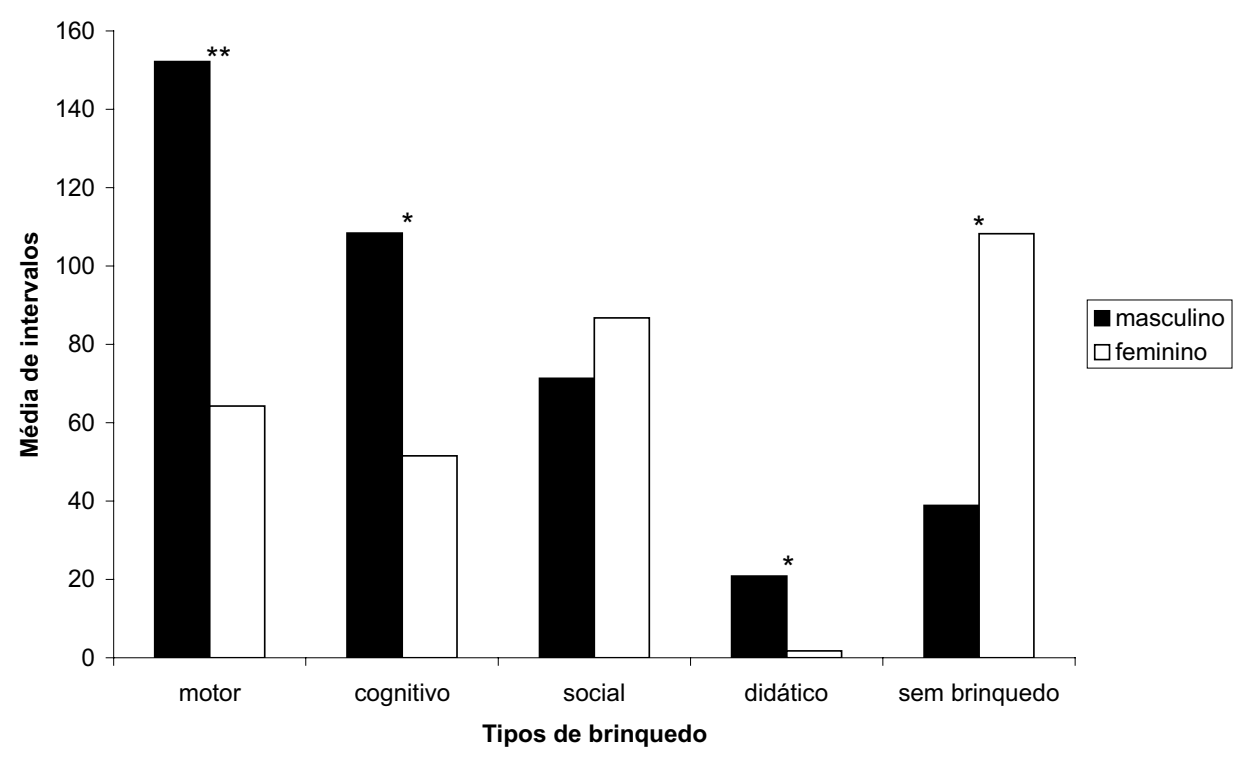

Figura 1. Média de intervalos observados da utilização dos vários tipos de brinquedos por sexo. ** Diferença altamente significativa $(p \leq 0,01) ;{ }^{*}$ Diferença significativa $(p \leq 0,05)$. 
Para verificar as diferenças de sexo sobre as médias de utilização dos brinquedos foi utilizado o teste $t$ de Student para amostras independentes. O teste $t$ indicou que os meninos brincaram mais que as meninas com brinquedos relacionados ao desenvolvimento motor, com diferença altamente significativa $[t(9)=3,33$; $p \leq 0,01]$ e brinquedos relacionados ao desenvolvimento cognitivo, com diferença significativa $[t(9)=2,39$; $p \leq 0,05)]$. Os brinquedos didáticos, apesar do baixo índice de utilização pelo grupo, também foram mais utilizados pelos meninos do que pelas meninas $[\mathrm{t}(9)=2,28 ; \quad p \leq 0,05)]$. As meninas apresentaram diferença significativamente estatística sobre os meninos apenas na categoria sem brinquedo $[(t(9)=2,45$; $p \leq 0,05)]$.

A categoria condizente ao tipo de atividade desenvolvida pelas crianças divide-se primeiramente em duas outras grandes categorias, as atividades de brincadeira e de não brincadeira. De forma geral, as crianças ficaram $77,4 \%$ dos intervalos observados em situações de brincadeira e $22,6 \%$ em atividades consideradas como não brincadeiras. Na diferença sobre os sexos os meninos tiveram $84 \%$ dos intervalos observados em situações de brincadeiras e $16 \%$ em atividades não relacionadas ao brincar. As meninas apresentaram $65,6 \%$ de intervalos observados em atividades de brincadeiras e $34,4 \%$ de atividades de não brincadeiras.

Dentre as atividades de brincadeira, as crianças demonstraram maior preferência por utilizar aquelas que são propostas pelo objeto (brinquedo), com $49 \%$ dos intervalos observados, jogos e regras com $24 \%$, turbulenta (18\%), faz-de-conta $(7 \%)$ e brincadeira turbulenta (3\%). A ANOVA de um fator para medidas repetidas, através do teste Greenhouse-Geisser, apontou haver diferença altamente significativa entre as cinco médias referentes aos tipos de brincadeiras $(F(2,21)=16,73, p \leq 0,01)$. Ao parear as médias para analisar o nível de significância das suas diferenças o teste Bonferroni indicou que as crianças têm preferência altamente significativa para utilizar a brincadeira proposta pelo objeto quando comparado com as demais categorias $(p \leq 0,01)$. Contudo, houve uma exceção para a brincadeira turbulenta, que pelo seu elevado índice de desvio padrão, não apresentou diferença estatística significativa quando pareada com as outras modalidades de brincadeira.

O brincar construtivo foi a modalidade menos utilizada pelas crianças, apresentando diferença altamente significativa entre as outras categorias $(p \leq, 01)$. Para verificar a diferença entre os sexos na escolha do tipo de brincadeira novamente foi utilizado o teste $t$ de Student para amostras independentes. Tanto os meninos quanto as meninas tinham preferência por utilizar os brinquedos de acordo com a proposta sugerida pelo objeto (Figura 2). Contudo, quando essa proposta não era seguida, as meninas se diferenciaram dos meninos pelas brincadeiras de faz-de-conta $[t(9)=8,26 ; p \leq 0,01)]$. Os meninos apresentaram diferença altamente significativa sobre as brincadeiras das meninas somente no brincar turbulento $[t(9)=2,34 ; p \leq 0,01)]$. Os jogos de regras tiveram igual preferência por meninos e meninas e o brincar construtivo pouco foi utilizado. 


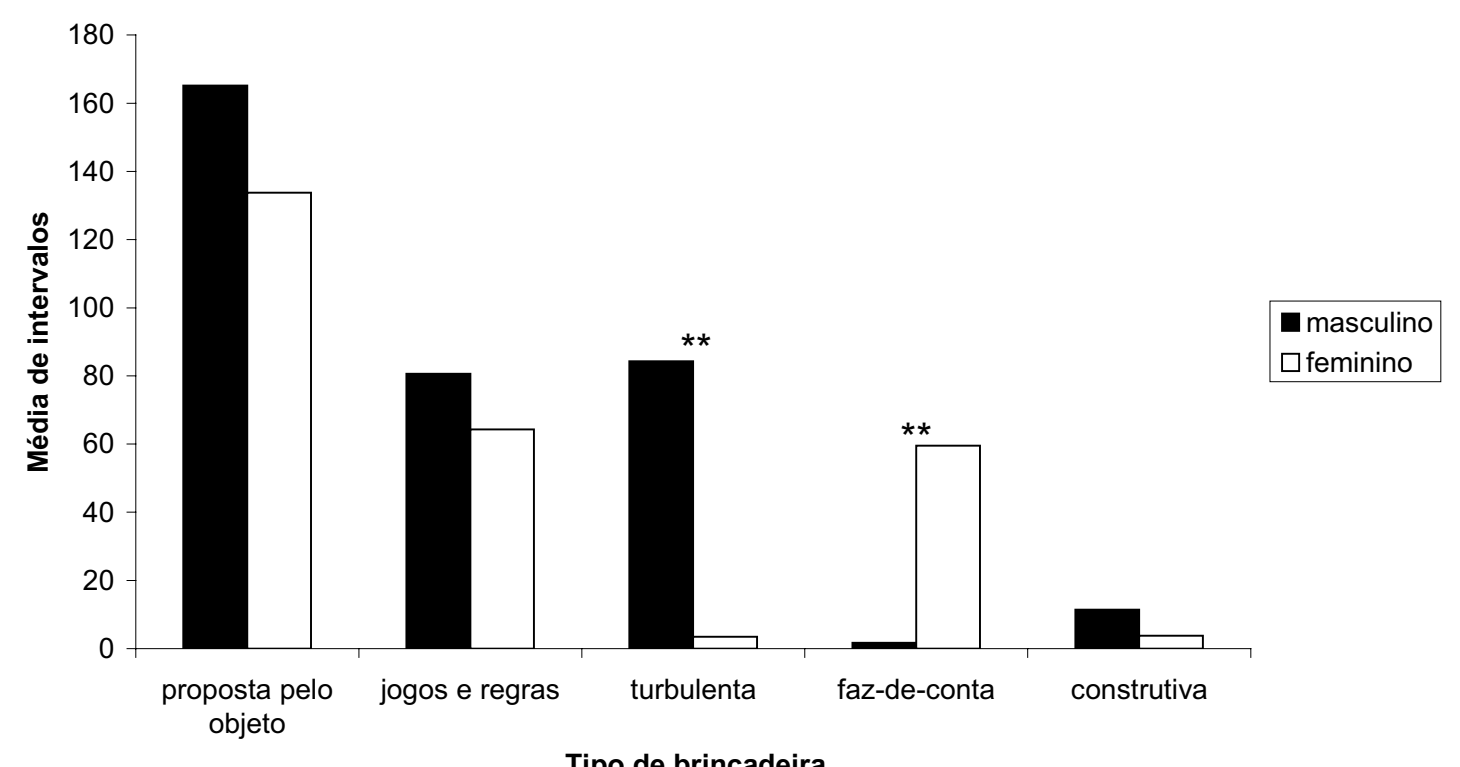

Figura 2. Média de intervalos observados da escolha das várias modalidades de brincadeiras por sexo.

${ }^{* *}$ Diferença altamente significativa $(p \leq 0,01)$.

\section{DISCUSSÃO E CONCLUSÕES}

Os resultados da presente pesquisa indicaram que as crianças têm preferências por brincar de forma grupal e segregada pelos sexos. O tipo de brinquedo didático é o menos utilizado pelas crianças quando comparado com os outros tipos. Foram encontradas diferenças significativas entre os meninos e as meninas no que se refere aos tipos de brinquedos e às atividades desenvolvidas. Os meninos têm preferência por brinquedos motores e cognitivos, enquanto que as meninas preferiam os brinquedos sociais. Além das brincadeiras propostas pelo objeto, os meninos se utilizavam mais de brincadeiras turbulentas enquanto que as meninas preferiam o faz-de-conta. As meninas, quando não estavam brincando preferiam atividades de conversação e de observação do ambiente.

Quanto à interação social, a preferência demonstrada pelas crianças para atividades e brincadeiras em grupos se mostra benéfica porque pode promover os contatos sociais, a aprendizagem de comportamentos, diferentes papéis, limites e sanções para os comportamentos ditos como não apropriados para uma determinada sociedade. Ou seja, o grupo de brincadeira pode agir como um mediador nos processos de ensino aprendizagem das regras sociais e cognitivas de uma cultura (Carvalho \& Pedrosa, 2002; Pedrosa \& Carvalho, 1995;
Silva \& cols., 2006). Além disso, como afirmam Pontes e Magalhães (2003), dificilmente um grupo irá apresentar sujeitos com o mesmo nível de habilidades. Desta forma, as crianças ao observarem seus colegas, além de poderem exercitar suas habilidades, também terão a oportunidade de aprender novas táticas e estratégias que poderão auxiliar nas brincadeiras atuais e nos contatos futuros (Bobato, 2002; Kishimoto, 1998; Morais, Otta \& Scala, 2001; Pellegrini \& Smith, 1998).

A composição do grupo, outro aspecto observado, também se mostra relevante, uma vez que os membros do grupo influenciam nas escolhas e conteúdos das brincadeiras e comportamentos. Os dados encontrados sobre a composição dos grupos e as formas de interações sociais das crianças nos permitem extrair suposições sobre o fenômeno da segregação sexual. O fato de as meninas brincarem com parceiros de ambos os sexos pode ser um indicador da composição do grupo observado, que era composto por apenas quatro meninas. Pode-se deduzir que essa circunstância pode ter exigido a presença de parceiros masculinos nas brincadeiras. Contudo, os dados de forte segregação pelos sexos, encontrados entre os meninos, vêm ao encontro com os dados de Silva e cols. (2006) que, ao observar a brincadeira de rua das crianças também constataram uma maior segregação pelos sexos por parte dos 
meninos. Cordazzo e Vieira (2008) ao entrevistarem crianças em idade escolar também verificaram que a segregação pelos sexos é mais forte entre os meninos e quase nula entre as meninas. Da mesma forma, Souza e Rodrigues (2002) observaram que as brincadeiras livres das crianças em idade escolar, na maioria das vezes, se apresentavam de forma mais segregada por parte dos meninos.

Outro resultado obtido foi que as crianças, de ambos os sexos, brincaram pouco com os brinquedos didáticos. Coloca-se aqui a hipótese de que isto acontece por que os brinquedos didáticos têm um objetivo final explícito, como o aprendizado de conteúdos escolares, enquanto que os outros brinquedos primam pelo prazer do brincar. Uma vez que a brincadeira tem um fim em si mesmo, conclui-se que as crianças não vêem os brinquedos didáticos como uma forma de brincadeira, e sim como uma atividade escolar.

A utilização dos brinquedos e jogos de regras na escola colabora não só para a aprendizagem infantil, mas também para o aperfeiçoamento da autorregulação dos comportamentos por parte das crianças. Pontes e Magalhães (2003) afirmam que a finalidade das regras do jogo é regular os comportamentos das crianças possibilitando estratégias para o desenrolar da brincadeira. Sendo assim, os jogos de regras também contribuem para que a criança aprenda a seguir regras na sociedade, fazendo um ensaio para a vida adulta (Pontes \& Magalhães, 2003).

Também foi verificada, através das observações, a preferência das crianças por utilizarem os brinquedos motores, principalmente por parte dos meninos. A brincadeira motora possibilita para as crianças a oportunidade de testar e exercitar suas habilidades físicas, bem como também controlar o peso, a termorregulação e as condições cardiorrespiratórias (Pellegrini \& Smith, 1998). Aliada a preferência por brinquedos motores também foi observada a utilização de brincadeiras turbulentas, principalmente pelos meninos. Quanto às brincadeiras turbulentas, Papalia e cols. (2006) afirmam que esta modalidade de brincadeira parece agressiva, pois envolve socos, chutes e perseguição, porém ela é de fato lúdica. Pellegrini e Smith (1998) afirmam que a brincadeira turbulenta proporciona benefícios às crianças por exigir um alto consumo de energia. Além disso, o brincar turbulento está intimamente ligado à aquisição de habilidades para lidar com situações que possam colocar a criança em risco físico. A brincadeira turbulenta também pode ajudar na aquisição de habilidades sociais, pois ao brincar de luta, por exemplo, a criança irá aprender a controlar seus impulsos, assim como o ganhar e o perder. Segundo Smith (1997) é por meio da brincadeira turbulenta que a criança desenvolve o controle emocional e habilidades cognitivas para distinguir as provocações dos colegas, entre sinais lúdicos e agonísticos.

\section{CONSIDERAÇÕES FINAIS}

Os dados obtidos através das observações das brincadeiras das crianças indicam que as crianças em idade escolar ainda apresentam forte motivação para a brincadeira. Tal motivação deve ser aproveitada pela instituição escolar uma vez que o brincar proporciona condições para a experimentação de diferentes tipos de interações sociais e favorece o desenvolvimento das crianças. Os dados de segregação por sexos encontrados sugerem que as escolas e os professores se estruturem de tal forma que estimulem a interação das crianças com pares de outro sexo. Este tipo de interação é benéfico uma vez que as crianças experimentam novas formas de interação, diferentes estratégias de resolução de conflitos e outros tipos de comportamentos.

O ambiente escolar é um espaço privilegiado onde as crianças podem se encontrar com um grupo grande de sujeitos da mesma faixa etária e então interagirem. Contudo, pelas demandas sociais e exigências escolares, muitas vezes as crianças têm reduzidos momentos de interação livre sem a interferência direta dos adultos. Queiroz e cols (2006) discutem sobre a necessidade de os profissionais da educação construírem ambientes que incentivem o brincar, uma vez que a brincadeira influencia positivamente no desenvolvimento infantil e compartilha os significados culturais de uma sociedade. Ao propiciar para as crianças períodos de brincadeiras livres, os profissionais que lidam com as crianças no contexto escolar, estarão reconhecendo o valor do brincar e aproveitando isto como um recurso para alcançarem seus objetivos com as crianças.

Os resultados deste estudo também sugerem novos rumos e possibilidades de pesquisas. A observação direta das crianças possui algumas limitações, tais como a ausência de neutralidade do observador e a sua possível influência nos comportamentos das crianças. Tendo isso em vista se faz necessário que outras pesquisas, com a utilização de diferentes instrumentos, sejam realizadas para também caracterizar as peculiaridades do brincar das crianças. Estudos que observem o brincar de crianças com dificuldades de aprendizagem e déficits no desenvolvimento também são ricas fontes de dados que poderiam aumentar o 
conhecimento a respeito dos comportamentos infantis. Ao conhecer as características do brincar e suas respectivas influências no desenvolvimento infantil, os profissionais que lidam com crianças terão mais recursos e estratégias para utilizarem em seus respectivos trabalhos. Trabalhos estes que devem ter o intuito de ampliar as possibilidades de desenvolvimento infantil e, consequentemente, fornecer melhores condições para a que as crianças exercitem e adquiram novas habilidades e estratégias que lhes auxiliarão tanto de forma imediata quanto em longo prazo.

\section{REFERÊNCIAS}

Baptista da Silva, C. C. (2003). O lugar do brinquedo e do jogo nas escolas especiais de educação infantil. Tese de doutorado não-publicada, Universidade de São Paulo.

Biscoli, I. Â. (2005). Atividade lúdica uma análise da produção acadêmica brasileira no período de 1995 a 2001. Dissertação de mestrado não-publicada, Universidade Federal de Santa Catarina.

Bjorklund, D. F., \& Pellegrini, A. D. (2000). Child development and evolutionary psychology. Child Development, 71(6), 16871708.

Blatchford, P. (1998). The state of play in schools. Child Psychology \& Psychiatry Review, 3(2), 58-67.

Bobato, S. T. (2002). Análise estrutural e funcional das interações sociais e do comportamento agressivo de crianças préescolares. Dissertação de mestrado não-publicada, Universidade Federal de Santa Catarina.

Bomtempo, E. (1997). Brincando se aprende: Uma trajetória de produção científica. Tese de livre-docência não-publicada, Universidade de São Paulo.

Brougère, G. (1998). A criança e a cultura lúdica. Revista da Faculdade de Educação, 24(2), 103-116.

Carvalho, A. M., Alves, M. M. F., \& Gomes, P. L. D. (2005). Brincar e educação: Concepções e possibilidades. Psicologia em Estudo, 10(2), 217-226.

Carvalho, A. M. A., \& Pedrosa, M. I. (2002). Cultura no grupo de brinquedo. Estudos de Psicologia, 7(1), 181-188.

Cordazzo, S. T. D., Westphal, J. P., Tagliari, F. B., Vieira, M. L., \& Oliveira, A. M. F. (2008). Metodologia observacional para o estudo do brincar na escola. Avaliação Psicológica, 7(3), 427438.

Cordazzo, S. T. D., Martins, G. D. F., Macarini, S. M., \& Vieira, M. L. (2007). Perspectivas no estudo do brincar: Um levantamento bibliográfico. Revista Aletheia, 26(1), 122-136.

Cordazzo, S. T. D., \& Vieira, M. (2008). Caracterização de brincadeiras de crianças em idade escolar. Psicologia: Reflexão e Crítica, 21(3), 365-373.
Fagundes, A. J. F. M. (1999). Descrição, definição e registro de comportamento (12 ${ }^{\mathrm{a}}$ ed.). São Paulo: EDICON.

Hansen, J., Macarini, S. M., Martins, G. D. F., Wanderlind, F. H., \& Vieira, M. L. (2007). O brincar e suas implicações para o desenvolvimento infantil a partir da psicologia evolucionista. Revista Brasileira de Crescimento e Desenvolvimento Humano, 17(2), 133-143.

Kishimoto, T. M. (1998). O brincar e suas teorias. São Paulo: Pioneira.

Kreppner, K. (2001). Sobre a maneira de produzir dados no estudo da interação social. Psicologia: Teoria e Pesquisa, 17(2), 97107.

Lordelo, E. R., \& Carvalho, A. M. A. (2006). Padrões de parceria social e brincadeira em ambientes de creches. Psicologia em Estudo, 11(1), 99-108.

Michelet, A. (1998). Classificação de jogos e brinquedos: A classificação ICCP. Em A. Friedmann, C. Aflalo, C. M. R. J. Andrade, \& R. Z. Altaman (Orgs.). $O$ direito de brincar: $A$ brinquedoteca (4 ed.) (pp. 160-172). São Paulo: Brincare.

Morais, M. L. S. (2004). Conflitos e(m) brincadeiras infantis: Diferenças culturais e de gênero. Tese de doutorado não-publicada, Universidade de São Paulo.

Morais, M. L. S., Otta, E., \& Scala, C. T. (2001) Status sociométrico e avaliação de características comportamentais: Um estudo de competência social em pré-escolares. Psicologia: Reflexão e Crítica, 14(1), 119-131.

Papalia, D., Olds, S. W., \& Feldman, R. D. (2006). Desenvolvimento humano (D. Bueno, Trad.) ( $8^{\mathrm{a}}$ ed.). Porto Alegre: Artes Médicas.

Parten, M. B. (1933). Social participation among preschool children. Journal of Abnormal Psychology, 27, 243-269.

Pedrosa, M. I., \& Carvalho, A. M. A. (1995). A interação social e a construção da brincadeira. Cadernos de Pesquisa, 93, 60-65.

Pellegrini, A. D., \& Smith, P. K. (1998). Physical activity play: The nature and function of a neglected aspect of play. Child Development, 69(3), 577-598.

Pontes, F. A. R., \& Magalhães, C. M. C. (2003). A transmissão da cultura da brincadeira: Algumas possibilidades de investigação. Psicologia: Reflexão e Crítica, 16(1), 117-124.

Queiroz, N. L. N., Maciel, D. A., \& Branco, A. U. (2006). Brincadeira e desenvolvimento infantil: Um olhar sociocultural construtivista. Paidéia, 16(34), 169-179.

Silva, L. I. C., Pontes, F. A. R., Silva, S. D. B., Magalhães, C. M. C., \& Bichara, I. D. (2006). Diferenças de gêneros nos grupos de brincadeira na rua: A hipótese de aproximação unilateral. Psicologia: Reflexão e Crítica, 19(1), 114-121.

Smith, P. K. (1997). Play fighting and real fighting: Perspectives on their relationships. Em A. Schimidt, K. Atzwanger, K. Grammer \& K. Schäfer (Orgs.), New aspects of human ethology (pp. 47-64). New York: Plenum Press. 
Souza, F., \& Rodrigues, M. M. P. (2002). A segregação sexual na interação de crianças de 8 e 9 anos. Psicologia: Reflexão $e$ Crítica, 15(3), 489-496.

Vygostky, L. S. (1998). A formação social da mente: $O$ desenvolvimento dos processos psicológicos superiores (J. C. Neto, L. S. Menna Barreto \& S. C. Afeche, Trads.) (4a ed.). São Paulo: Martins Fontes.

Wajskop, G. (1996). Concepções de brincar entre profissionais de educação infantil: Implicações para a prática institucional. Tese de doutorado não-publicada, Universidade de São Paulo.
Wanderlind, F., Martins, G. D. F., Hansen, J., Macarini, S. M., \& Vieira, M. L. (2006). Diferenças de gênero no brincar de crianças pré-escolares e escolares na brinquedoteca. Paidéia, 16(34), 263-273.

\section{Sobre os autores:}

Sheila Tatiana Duarte Cordazzo: Graduação em Psicologia pela Universidade do Oeste de Santa Catarina (1999), mestrado em Psicologia pela Universidade Federal de Santa Catarina (2003) e doutorado pela Universidade Federal de Santa Catarina (2008).

Josielly Pinheiro Westphal: Graduanda do curso de Psicologia da Universidade Federal de Santa Catarina.

Fernanda Balem Tagliari: Graduanda do curso de Psicologia da Universidade Federal de Santa Catarina.

Mauro Luís Vieira: Professor do Departamento de Psicologia na Universidade Federal de Santa Catarina (UFSC). Doutor em Psicologia Experimental pela Universidade de São Paulo (1995). Pós-doutorado na Dalhousie University em Halifax, Canadá (1999). Trabalha na linha de pesquisa sobre cuidados parentais e desenvolvimento infantil no Programa de Pós-graduação em Psicologia da UFSC. Coordena o Núcleo de Pesquisa sobre Desenvolvimento Infantil.

Endereço para correspondência: Mauro Luís Vieira - Universidade Federal de Santa Catarina, Centro de Filosofia e Ciências Humanas, Departamento de Psicologia. Núcleo de Estudos e Pesquisas em Desenvolvimento Infantil Trindade - Caixa-Postal: 47 - 88049-900 Florianopolis/SC. Endereço eletrônico: maurolvieira@gmail.com. 